\title{
Esophageal Varices Hemorrhage
}

National Cancer Institute

\section{Source}

National Cancer Institute. Esophageal Varices Hemorrhage. NCI Thesaurus. Code C78282.

Bleeding from esophageal varices. 